\title{
A Brief Discussion on the Application of Film in Abnormal Psychology Teaching
}

\author{
Yanan Zheng, Biji Fang \\ Department of Psychology, Jiangxi Medical College, Ganzhou 341000, China \\ zhengyanan1233@163.com
}

\begin{abstract}
The abnormal psychology is a required basic specialty course of applied psychology specialty, and the film teaching should be regarded as one of the important teaching means for such course. Integrating the films relating to mental illness into abnormal psychology teaching has important effect and meaning in arousing the learning interest of the students, improving the identification and diagnostic capabilities of the students to various mental illnesses, enhancing the understanding of the students to mental illness, and developing the communication and expression abilities of the students, etc. This teaching method is worthy of further promotion in the teaching of abnormal psychology and other subjects of applied psychology specialty.
\end{abstract}

Keywords: film teaching; abnormal psychology; mental illness

With the development of multimedia technology, audio-visual teaching has become an indispensable part of modern teaching, while the films have the incomparable advantage compared with other media because of its visual, vivid and appealing characteristics [1]. Learning part of the course content through film and television appreciation has been adopted by more and more teachers.

The abnormal psychology is a branch discipline of psychology, and it studies abnormal psychology and behavior and its regular [2], the course is one of the required basic specialty courses for the students of applied psychology specialty. However, the diagnosis of various abnormal psychologies in mental illness are empty and lack of appropriate clinical practice, which results that it's difficult to properly master the diagnose of the various mental illnesses and understand the corresponding clinical manifestation, the students generally reflect that learning the subjects is difficult, and the theory is disconnected with the practice. The students are able to have a certain understanding of the concept of mental illness and clinical manifestation when finished the relevant theory teaching, but it is difficult for them to apply the theory to practice, because it is easy to confuse some mental illnesses in actual works. Through selecting appropriate films related to mental illness, reasonably arranging the teaching content and giving corresponding thinking topic and organizing the students to carry out relevant case discussion, we can effectively improve the learning effect of the students, enhance the learning interest of the students to abnormal psychology, that will enable them better understandings of the clinical manifestation and diagnostic criteria of various mental illnesses, and achieve good teaching effect. 


\section{Implementation of Abnormal Psy- chology Film Teaching Method}

\subsection{Selection of relevant films}

Selecting proper course-related films is the key to the successful implementation of film teaching. A film relating to mental illness symptoms with plentiful and vivid contents will impress the students much, through the discussion after the film, it is easy to make the students master the diagnostic and clinical manifestation of the mental illness. Such as in the teaching process of schizophrenia and other psychotic disorders chapters, we can choose to watch the film "A Beautiful Mind", through the experience and achievements of mathematician Nash in film and television works, it is easy to make the students understand the schizophrenics.

\subsection{Preparations before the film showings}

To make the students grasp the mental illnesses in film and television works better, we need to complete the theory teaching before the film showings, so as to ensure that the students can understand the psychological problems in the film, for example, before showing the film "A Beautiful Mind", we need to detail the concept, clinical manifestation, etiology and pathogenesis, clinical classification, diagnosis and differential diagnosis and relevant treatment programs of schizophrenia, and show typical schizophrenia case if possible.

\subsection{Film showings}

In the process of film showings, aiming at some of the complex and confusing psychotic symptoms, the teacher can pause the film play for further explanation, so as to ensure that the students can understand the clinical manifestation of the mental illness; for some typical symptoms, the teacher may play back repeated- ly to deepen the impression of the illness; in case that the manifestation of some mental illnesses are not obvious and have little to do with the main plot, we can skip such section and explain the corresponding case discussion.

\subsection{Relevant discussions after the film showings}

After the film showings, the teacher should raise some questions for the mental illness in the film, and organize the students for class discussions in groups, for example, diagnosis of the mental illness showed by the film roles, diagnosis basis, which behavior of the role in the film shows psychotic symptoms, putting forward reasonable treatment programs according to the clinical manifestation. In consideration of the professional level of the students and the lack of experience in clinical practice, the teacher should summarize according to the students' speaks, and explain the diagnostic criteria of relevant mental illness combining with the film, so as to improve the students' capacity of linking theory with practice [4].

\section{Significance of Abnormal Psycholo- gy Film Teaching}

\subsection{Improve the learning interest of the students to abnormal psy- chology}

In the process of teaching, the abnormal psychology has various problems, such as theory divorced from practice, rigid teaching contents and boring course, difficult to raise the interest of the students, poor attraction to the students, and the film teaching helps to stimulate the learning interest of the students to abnormal psychology and mobilizes the learning enthusiasm of the students, so as to improve the learning efficiency; meanwhile, through the students' analysis of various mental illnesses in film and television 
works, we can improve the abilities of the students to independently think, find out and solve the problem.

\subsection{Improve the identification and diagnostic capabilities of the stu- dents to various mental illnesses}

Combining film teaching in the process of abnormal psychology teaching can vividly show the clinical manifestation of various mental illnesses, this will make the abstract theory more specific and intuitive, help the students to grasp the diagnostic points of mental illness in the film, and change the traditional duckstuffing type of teaching method of "teacher talks, students mechanically memorize"; according to the discussion situation of the students, the teacher should summarize the discussion results, enhance the students' understanding of the disease, so as to link theory with practice and achieve the teaching purpose.

\subsection{Enhance the understanding of the students to mental illness}

Due to the impact of traditional concepts, the majority of the students still have prejudice on the various types of abnormal behaviors and discrimination to patients with mental illness, they may think that patients with mental illness are useless, but many defects, for example, a considerable part of the students of applied psychology specialty believe that schizophrenics have defects in intelligence, memory and even moral, or serious violent tendencies, and the views of the students' to schizophrenia change in a considerable extent by watching the film "A Beautiful Mind".

\subsection{Upgrade the teacher-student in- teraction and develop the com- munication and expression abili- ties of the students}

After watching the film, the views of the students on the characters' mental illness, aetiological agent, clinical manifestation, feasible treatment programs in film and television works will be discussed, the teacher should conclude the discussion; it can increase the teachers and students communication. At the same time, we can ask the students to act the patients and doctors in the film in accordance with their distinctive images, and design realistic scene to make them personally on the scene, and complete the interrogation process and put forward reasonable intervention programs [5], so as to deepen the students' understanding of the contents and improve related skills in talks, diagnosis and psychological counseling.

\section{Matters Needing Attention When Integrating the Film Teaching into Abnormal Psychology Teaching}

\subsection{Chosen teaching films need to meet the teaching requirements}

The film teaching is an assistant teaching mean, and other parts play more important roles in helping the students to grasp the meaning of the relevant mental illness, including theoretical instruction before the film showings, discussion after the film showings, teacher's summarization and presentation extent of all kinds of psychological problems in the film. In the process of teaching, films can not be selected at random, such as simply choosing the "blockbuster" while ignoring the teaching purpose. Therefore, although mental illness is involved in some of the films, but the plot is too vivid and suspense with a huge amount of information, such as Shutter Island, it is not suitable for teaching purpose. 


\subsection{Lower professional standard of the students and in-depth expla- nation on related mental illness}

The diagnostic criteria and clinical manifestation of mental illness is extremely complex, if fails to explain the characteristic details of related diseases before the film showings, the students may feel difficult to understand the role symptoms in the film, and if fails to explain and summarize the diseases in the film with group discussion after film showings, the students may easily regard the film teaching as an entertainment, and the film teaching is a mere a formality, both of the above situations may affect the teaching effect. Therefore, in the process of abnormal psychology film teaching, the teacher still needs to play a leading role, through the appropriate theory explanation, discussion and summarization after film showings, so as to achieve the teaching purpose, and the teacher should not act a role in the film showings [6].

\subsection{Film teaching effect depends on the level of the teacher}

The teacher needs to have certain psychological clinical experience and higher teaching level, so as to understand the clinical symptoms of mental illness of the film roles, as well as reasonably guide and organize the students to explain, discuss, summarize and review the case in the film. Therefore, the film teaching effect of abnormal psychology depends on the level of the teacher to a considerable extent.

\section{Conclusion}

In conclusion, we should flexibly apply the film teaching in the teaching of abnormal psychology and psychology practical subjects (such as psychological counseling and therapy) of applied psychology specialty, carry out active and multi-modal learning activities taking the students as the center as much as possible, so as to maximize the students to participate in and actively learn [7], it is possible to improve the shortcomings of traditional theoretical teaching, and fully mobilize the learning enthusiasm of the students and completely improve the learning interest and learning efficiency, and the students will master the theoretical knowledge and skills and apply it in practice by watching film and case discussion, so as to improve the students' abilities to link theory with practice and to solve practical problems.

\section{References}

[1] Wei Qi. Discussion on Teaching of Current Foreign Language Film Course by Example Teaching, Film Literature, 2011.4: 150-151.

[2] Liu Xinmin. Abnormal Psychology, Beijing: People's Medical Publishing House, 2007.

[3] Xu Xueqin. Discussion on College Chinese Teaching Introducing Films to Assist and Realize Teaching Goals, Journal of Shanxi Youth Management Cadre College, 2010.23 (2): 104-105

[4] Hu Yongdong. Application of Film Teaching Method of Pathergasiology in Chinese Medicine, Chinese Medical Record, 2012.13 (1): 56-57

[5] Li Gongying. Application of Scenario Simulation Teaching Method in Pathergasiology Teaching, Journal of Jining School of Medicine, 2011.34 (4): 293-295

[6] Zhu Zhenxia, Li Mingqiang. A brief Discussion on the Application of Film in College Korean Listening Teaching, Film Literature, 2010.10: 146147

[7] Guo Zhibin. Humanism-based Multimodal English Television Teaching, Film Literature, 2010.22:150-151. 